DOI: 10.17516/1997-1397-2021-14-4-492-496

УДК 539.374

\title{
Distribution of Zones of Elastic and Plastic Deformation Appearing in a Layer under Compression by Two Rigid Parallel Plates
}

\author{
Olga V. Gomonova* \\ Sergey I. Senashov ${ }^{\dagger}$
}

Reshetnev Siberian State University of Science and Technology

Krasnoyarsk, Russian Federation

Olga N. Cherepanova

Siberian Federal University

Krasnoyarsk, Russian Federation

Received 10.03.2021, received in revised form 05.04.2021, accepted 20.05.2021

Abstract. A problem of distribution of zones of elastic and plastic deformation appearing in a layer of elasto-plastic material under compression by two rigid parallel plates, for the case of plane strain state with Tresca - Saint-Venant yield criterion is solved. The technique based on application of conservation laws is used to solve the problem.

Keywords: layer compression, elasto-plastic problem, conservation laws, plane strain state.

Citation: O.V. Gomonova, S.I. Senashov, O.N. Cherepanova, Distribution of Zones of Elastic and Plastic Deformation Appearing in a Layer under Compression by Two Rigid Parallel Plates, J. Sib. Fed. Univ. Math. Phys., 2021, 14(4), 492-496. DOI: 10.17516/1997-1397-2021-14-4-492-496.

It this work, a problem of compression of a layer of elasto-plastic material between two rigid parallel plates is considered, and a distribution of zones of elastic and plastic deformation appearing in the layer for the case of a plane strain state is obtained. An elasto-plastic problem is solved to find zones of deformation. As it is known, the complexity of such problems is in finding of an elasto-plastic boundary separating regions of elastic and plastic deformation. An overview of elasto-plastic problems and the methods of their solving are presented in [1]. One should note that the methods of functions of the complex variable theory are the main tool of solving of these problems.

In the present work, a technique based on construction of conservation laws for differential equations is used to solve the considered problem [2-4]. The proposed technique has been applied successfully to find solutions of elasto-plastic problems of the torsion of rods and the bending of uniform cross-section beams [5-6], and to solve the problem of construction of elasto-plastic boundary in a deformed rectangular plate weakened by holes [7].

*gomonova@sibsau.ru

${ }^{\dagger}$ sen@sibsau.ru https://orcid.org/0000-0001-5542-4781

${ }^{\ddagger}$ cheronik@mail.ru

(c) Siberian Federal University. All rights reserved 


\section{Problem statement}

We study a layer of elasto-plastic material of the length $l$ and the width $h$ compressed between two rigid parallel plates (Fig. 1).

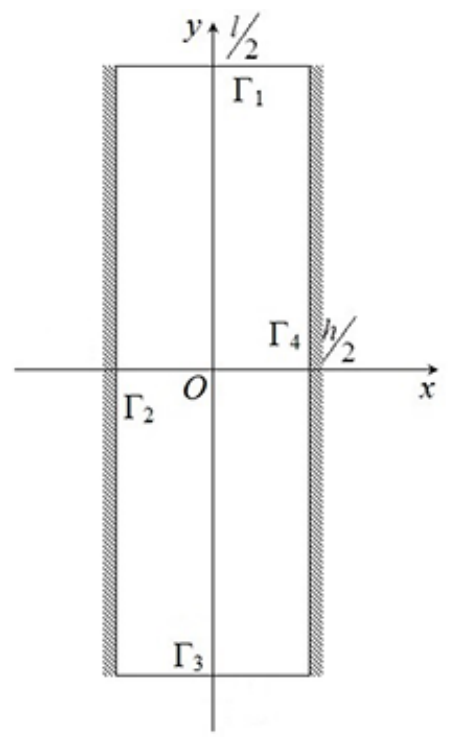

Fig. 1. Layer of Material Compressed Between Two Rigid Plates

The contour $\Gamma=\Gamma_{1}+\Gamma_{2}+\Gamma_{3}+\Gamma_{4}$ bounding the layer is given as follows:

$$
\begin{array}{llll}
\Gamma_{1}: y=\frac{l}{2}, & \frac{h}{2}<x<-\frac{h}{2} ; & \Gamma_{2}: x=-h / 2, & \frac{l}{2}<y<-\frac{l}{2} ; \\
\Gamma_{3}: y=-\frac{l}{2}, & -\frac{h}{2}<x<\frac{h}{2} ; & \Gamma_{4}: x=h / 2, & -\frac{l}{2}<y<\frac{l}{2} .
\end{array}
$$

It worth noting that for further numerical calculations the following values of the layer size are chosen: $l=0.1 \mathrm{~m}$ and $h=0.02 \mathrm{~m}$.

The layer is compressed along the axis $O x$. The boundaries $\Gamma_{1}$ and $\Gamma_{3}$ are free from external loading. It is supposed that the contour $\Gamma$ is in plastic state.

One should solve an elasto-plastic problem for the domain bounded by $\Gamma$ to determine zones of elastic and plastic deformation. In the case of plane strain state, components of the stress tensor $\sigma_{x}, \sigma_{y}, \tau$ satisfy the equilibrium equations:

$$
\frac{\partial \sigma_{x}}{\partial x}+\frac{\partial \tau}{\partial y}=0, \quad \frac{\partial \sigma_{y}}{\partial y}+\frac{\partial \tau}{\partial x}=0 .
$$

The compatibility equation holds in elastic domain:

$$
\Delta\left(\sigma_{x}+\sigma_{y}\right)=0 .
$$

The yield criterion of Tresca - Saint-Venant for the case of plane strain state on the contour $\Gamma$ has the form:

$$
\left(\sigma_{x}-\sigma_{y}\right)^{2}+4 \tau^{2}=4 k^{2},
$$

where $k$ is a constant of material plasticity. 
The boundary conditions for the layer are written as:

$$
\sigma_{x} n_{1}+\tau n_{2}=X, \quad \sigma_{y} n_{2}+\tau n_{1}=Y .
$$

Here $X, Y$ are the components of external force and $n_{1}, n_{2}$ are the components of normal vector to the contour $\Gamma$.

Taking into consideration the last equations and the yield criterion (4), one can obtain the following values of normal and tangential stresses on $\Gamma$ : on the boundaries $\Gamma_{1}, \Gamma_{3}$

$$
\sigma_{x}= \pm 2 k, \quad \sigma_{y}=0, \quad \tau=0
$$

and on the boundaries $\Gamma_{2}, \Gamma_{4}$

$$
\sigma_{x}=-2 k, \quad \sigma_{y}=0, \quad \tau=0 .
$$

\section{Solving the problem using conservation laws}

A technique based on application of conservation laws is used to solve this elasto-plastic problem. One can find the description of the technique in details in [7].

Solution of the problem consists of three main steps.

First, the Laplace equation $\Delta F=0$ with boundary conditions $\left.F\right|_{\Gamma}=\sigma_{x}+\sigma_{y}$ is solved (where $\sigma_{x}, \sigma_{y}$ are functions from (4)-(5), $F=\sigma_{x}+\sigma_{y}$ is a harmonic function from (3)).

Let $\sigma_{x}=2 k$ on $\Gamma_{1}, \Gamma_{3}$ (see (6)), then one gets $\left.F\right|_{\Gamma_{1}, \Gamma_{3}}=2 k$. Also, from $(7),\left.F\right|_{\Gamma_{2}, \Gamma_{4}}=-2 k$.

Further on, the finite element method is employed to find the values of the function $F$ in every point $\left(x_{0}, y_{0}\right)$ of region bounded by the contour $\Gamma$.

Second, values of the functions $\sigma_{x}, \tau$ are found in each point $\left(x_{0}, y_{0}\right)$ of the region applying the formulae obtained using the conservation laws:

$$
\sigma_{x}\left(x_{0}, y_{0}\right)=\frac{1}{2 \pi} \int_{\Gamma}\left(\omega_{1}^{1} \sigma_{x}+\omega_{1}^{2} \tau+f_{1}\right) d y-\left(-\omega_{1}^{2} \sigma_{x}+\omega_{1}^{1} \tau+g_{1}\right) d x,
$$

where $f_{1}=0, g_{1}=\int \omega_{1}^{2} d_{y} F$ and $\omega_{1}^{1}=\frac{x-x_{0}}{\left(x-x_{0}\right)^{2}+\left(y-y_{0}\right)^{2}}, \omega_{1}^{2}=-\frac{y-y_{0}}{\left(x-x_{0}\right)^{2}+\left(y-y_{0}\right)^{2}}$;

$$
\tau\left(x_{0}, y_{0}\right)=\frac{1}{2 \pi} \int_{\Gamma}\left(\omega_{2}^{1} \sigma_{x}+\omega_{2}^{2} \tau+f_{2}\right) d y-\left(-\omega_{2}^{2} \sigma_{x}+\omega_{2}^{1} \tau+g_{2}\right) d x .
$$

Here $f_{2}=0, g_{2}=\int \omega_{2}^{2} d_{y} F ; \omega_{2}^{1}=\frac{y-y_{0}}{\left(x-x_{0}\right)^{2}+\left(y-y_{0}\right)^{2}}, \omega_{2}^{2}=\frac{x-x_{0}}{\left(x-x_{0}\right)^{2}+\left(y-y_{0}\right)^{2}}$.

Note that a detailed derivation of formulae (8-9) is given in [7].

From the definition of $F$ one can get values of the function $\sigma_{y}$ in points $\left(x_{0}, y_{0}\right)$ of the region bounded by $\Gamma$ :

$$
\sigma_{y}\left(x_{0}, y_{0}\right)=F-\sigma_{x}\left(x_{0}, y_{0}\right) .
$$

The third step of solving of the problem is in the yield criterion (4) verification in all inner points of the considered region. If the stresses in a point $\left(x_{0}, y_{0}\right)$ satisfy the condition

$$
\left(\sigma_{x}-\sigma_{y}\right)^{2}+4 \tau^{2}<4 k^{2},
$$

the point belongs to the elastic zone. If the inequality is not fulfilled, the point $\left(x_{0}, y_{0}\right)$ gets into the zone of plastic deformation.

Fig. 2 shows distribution of points forming zones of elastic and plastic deformation in the compressed layer. 


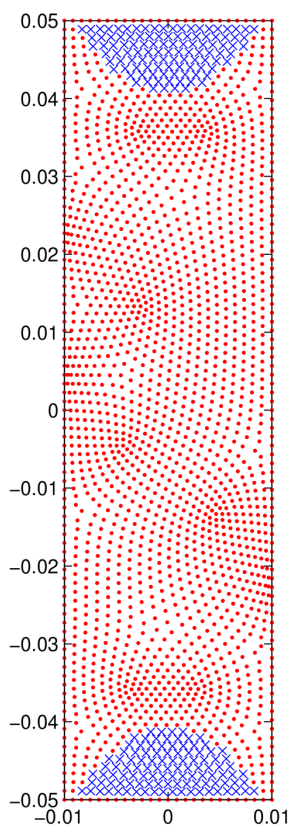

Fig. 2. Distribution of Zones of Elastic $(\times)$ and Plastic $(\cdot)$ Deformation in the Layer under Compression

\section{Conclusion}

A problem of compression of an elasto-plastic layer between two rigid parallel plates is considered for the case of plane strain state. Zones of plastic and elastic deformations are obtained using the technique based on the conservation laws application. Distribution of the zones of deformation is given using finite element method.

This work is supported by the Krasnoyarsk Mathematical Center and financed by the Ministry of Science and Higher Education of the Russian Federation in the framework of the establishment and development of regional Centers for Mathematics Research and Education (Agreement no. 075-02-2020-1631).

\section{References}

[1] B.D.Annin, G.P.Cherepanov, Elasto-plastic Problem, Nauka, Novosibirsk, 1983 (in Russian).

[2] Symmetries and Conservation Laws of Mathematical Physics Equations (I. S. Krasilshchik, A. M. Vinogradov (eds.)), Factorial Press, Moscow, 2005 (in Russian).

[3] P.P.Kiryakov, S.I.Senashov, A.N.Yakhno, Application of Symmetries and Conservation Laws to Solve Differential Equations, Branch of RAS, Novosibirsk, 2001 (in Russian).

[4] S.I.Senashov, O.V.Gomonova, A.N.Yakhno, Mathematical Questions of Two-Dimensional Equations of Ideal Plasticity, Reshetnev Siberian State Univ. of Sci. and Technol., Krasnoyarsk, 2012 (in Russian). 
[5] S.I.Senashov, O.N.Cherepanova, A.V.Kondrin, Elastoplastic Bending of a Beam, J. Sib. Fed. Univ. Math. Phys., 7(2014), no. 2, 203-208.

[6] S.I.Senashov, O.N.Cherepanova, A.V Kondrin, On Elastoplastic Torsion of a Rod with Multiply Connected Cross-Section, J. Sib. Fed. Univ. Math. Phys., 7(2015), no. 1, 343-351.

[7] S.I.Senashov, O.V.Gomonova, Construction of Elastoplastic Boundary in Problem of Tension of a Plate Weakened by Holes, Int. J. Nonlin. Mech., 108(2019), 7-9.

\title{
Распределение областей упругих и пластических деформаций, возникающих при сжатии слоя двумя жесткими параллельными плитами
}

\section{Ольга В. Гомонова \\ Сергей И. Сенашов}

Сибирский государственный университет науки и технологий им. М. Ф. Решетнева

Красноярск, Российская Федерация

Ольга Н. Черепанова

Сибирский федеральный университет

Красноярск, Российская Федерация

\begin{abstract}
Аннотация. В работе решена задача о распределении областей упругого и пластического деформирования, возникающих в слое упруго-пластического материала, сжимаемого двумя жесткими параллельными плитами, для случая плоского деформированного состояния с условием текучести Треска - Сен-Венана. При решении задачи была использована методика, основанная на применении законов сохранения.
\end{abstract}

Ключевые слова: сжатие слоя, упруго-пластическая задача, законы сохранения, плоское деформированное состояние. 